\title{
Comprehensive and Multidimensional Model: Life Therapy and Spiritual Psychotherapy for Prevention and Treatment of Addiction
}

\author{
M.D. Mohammad Reza Mohammadi \\ Tehran University of Medical Sciences, Iran \\ Msc. Soghra Zabihi Mahmoodabadi \\ Tehran University of Medical Sciences, Iran
}

\begin{abstract}
Individual, familial, social, economic, political, existential and spiritual factors all influence substance use. Lifestyle, quality of life, parenting style and parents' personality disorders and mental health problems, social capital, poverty and the largest globe businesses of illegal-drugs in the world have also share a significant effect on the addiction. One should consider all of those factors in order to efficiently prevention and treatment of the addiction. Each factor should be considered in the treatment and interventions.
\end{abstract}

Keywords: Comprehensive, Multidimensional Model, Life Therapy, Spiritual Psychotherapy, Prevention, Treatment, Addiction

\section{Introduction}

\section{Individual factors}

Individual, physiological, temperamental and personality factors are peculiar in each individual and are even different in identical twins. Due to some difficulties and shortcomings, some individuals are more prone to any addiction in general and addiction to substance in particular. Lifestyle, quality of life and parenting style are extremely important and much more effective.

\section{Familial factors}

The main pathology in addiction is the family pathology. Parents' personality disorders and mental health problems, social capital, lifestyle, quality of life and parenting style, either cause or prevent substance use in adolescents.

\section{Social, economic and political factors}

The largest globe businesses are 3: 1- petroleum, 2 - weapon, 3 - illegal drugs

Illegal drug trade is now the third largest business in the world and plays a significant Economic, social and political role. In Iran $74 \%$ of addicts use traditional substances and $26 \%$ use recreational ones. They cost 3.5 billion $\$$ and 1.75 billion $\$$ each year respectively. Total costs reach to 5.25 billion $\$$ annually. At least twice of that will be the cost of preventive and therapeutic interventions. $17-20 \%$ of adult population is addicted to tobacco. No country has paid the price for controlling substances as much as Iran did. More than 4000 martyrs and 12000 more injured in substance control operations.

For the life therapy or spiritual therapy, the concepts are applied to a therapeutic context of care and compassion which means love and belief beyond oneself. By cultivating a soulful and spiritual existence, thus conducting one's clinical practice on the basis of these tenets of transcendence, the therapist can guide the patient to reach his or her own authentic self. Changing the mechanisms, through changing psychotherapeutic techniques that will be named 'spiritual psychotherapy' and life therapy will be discussed.

1-Acceptant and trust 2- Reality Technique 3-Clarification 4-Responsibility 5- Love of self 6- Love of belonging 7- Love of work 8- Love of others 9- Forgiveness 10- spiritual light 11- Unity 12-Transformation 13-Recognition of behavioral 
consequences 14-Exclusion: give up, vomiting 15-Inclusion-Incorporation 16- Flexibility 17-Affective self-regulation 18Enhance introspective abilities 19-Introspective self-reflection 20-Analysis of: thoughts, emotions, aims and life 21-Control training of thoughts, emotions and behavior 22- Challenge solving 23- Reinforcement (permanent - temporary) 24-SelfMonitoring and Instruction training 25-Mirroring 26- Commitment 27-Appropriate response 28-Means of Trial and Error 29Modeling 30-When and how to control 31-Over control and under control 32-Appraising (critical) 33-Basic belief systems 34-Think locally, view globally and spirituality, act specifically 35-Future focusing (continuing of life). 